\title{
Loiomyoma of Epididymis
}

\section{BC Shah, Sarang Degloorkar, A Rao}

Department of Surgery, Bhakti Vedanta Hospital and Research Institute,

Srishti Complex, Mira Road East, Thane, Maharashtra - 401017, India.

\section{Abstract:}

The leiomyoma's which are benign tumors, can arise from any organ containing smooth muscle. In the genitourinary tract, the renal capsule is most commonly involved. Leiomyoma's in scrotal sac are infrequently seen. We report a rare testis-associated leiomyoma.

Key words: Testicular Neoplasms, Leiomyoma, Smooth Muscle, Urinary Tract, Urogenital System.

\section{Introduction}

Leiomyomas may arise from any tissue that contains smooth muscle. In genitourinary system, their most common locations are mentioned to be uterus and renal capsule. Epididymal leiomyoma's are welldefined intrascrotal tumors with a fibrous capsule. Although they are slowly growing tumors which tend to occur in adult age, patients with young age have been reported. These rare benign intrascrotal tumors may lead to orchiectomies because of suspicion of testicular malignancy.

\section{Case Report}

42 year old male presented with left sided testicular swelling since 5 years. This was gradually increasing in size with occasional dragging pain in left scrotum. He had no significant past history. On physical examination his left testis was normal in size with a firm to hard, non-tender swelling in the lower pole of left epididymis. Spermatic cord was unremarkable. Also the right testis, epididymis $\&$ spermatic cord were unremarkable.

Patient's complete blood count and routine blood biochemistry were within normal limits. The scrotal ultrasound showed hypervascular lesion in tail of left epididymis suggesting solid lesion in it. Left sided grade 2 varicocele was seen. The right sided testis, epididymis and hemi-scrotum were normal.

Patient underwent scrotal exploration. It showed enlarged left epididymis with presence of a well-defined globular mass at tail of epididymis [Fig. 1]. The mass was firm and nodular in consistency measuring $2.5 \times 3 \mathrm{cms}$ [Fig.2]. The mass was excised completely along with wall of epididymis. Biopsy of left testicular lesion revealed leiomyoma left testis. Cut section showed a well circumscribed mass with grey white firm appearance. Microscopic section

Corresponding Author: Dr. BC Shah

Email: vaishnavasevadasa@gmail.com

Received: May 2, 2015 | Accepted: July 27, 2015 | Published Online: August 15, 2015

This is an Open Access article distributed under the terms of the Creative Commons Attribution License (creativecommons.org/licenses/by/3.0)

Conflict of interest: None declared | Source of funding: Nil | DOl: http://dx.doi.org/10.17659/01.2015.0089 


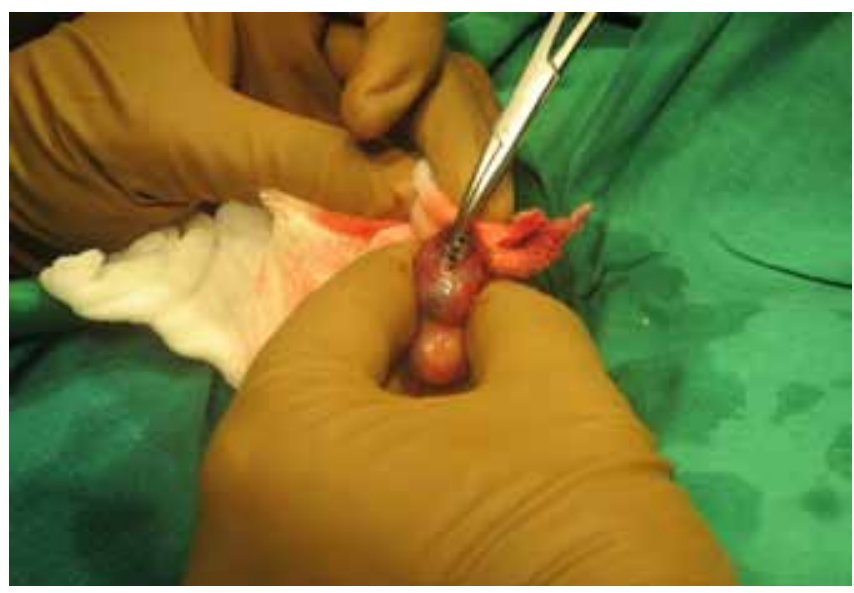

Fig.1: Leiomyoma of epididymis seen at tail of epididymis.

of testis showed a tumor composed of spindle shaped cells having blunt ended elongated nuclei and eosinophilic cytoplasm arranged in interlacing fascicles and bundles. There was no evidence of malignancy in examined sections.

\section{Discussion}

Epididymal tumors are rare. The incidence of leiomyoma of epididymis in white people is estimated to be $5 \%$ of epididymal masses, as opposed to $40 \%$ in Asian people [1]. Leiomyoma is the second most common primary neoplasm of the epididymis. Till now only 19 cases have been reported so far as we have researched [2]. They are benign, often bulky tumors that are derived embryologically from mesenchymal cells. Leiomyomas are also found throughout the genitourinary tract, in any organ containing smooth muscle. The most common site for leiomyoma in the urinary tract is the renal capsule after uterus. Even the ureter, bladder, urethra, prostate, seminal vesicles, penis, epididymis, spermatic cord, tunica dartos, tunica albuginea of the testicle and the testicle may be involved. Ultrasound is a widely used imaging modality for patients with suspected scrotal abnormalities [3].

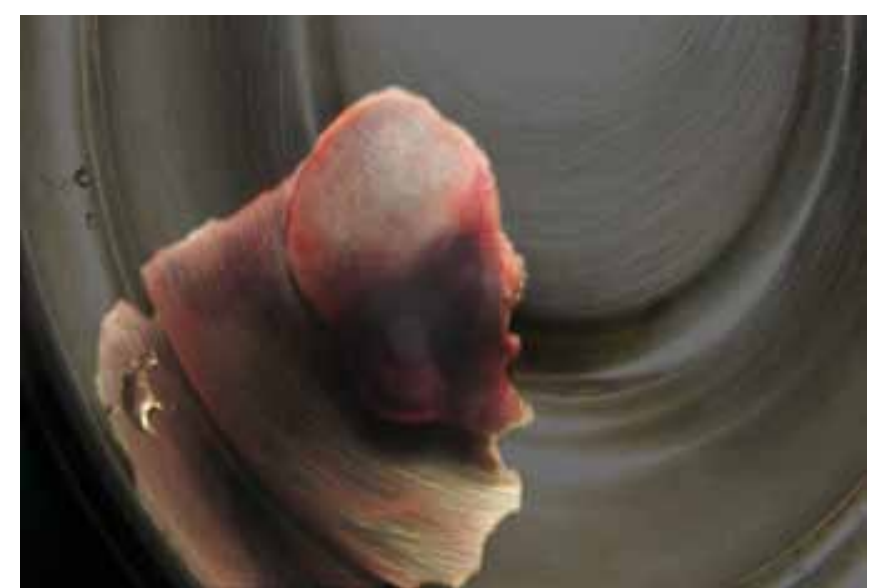

Fig.2: Leiomyoma of epididymis seen after excision.

With ultrasound, cystic lesion of the epididymis such as epididymal cysts and spermatoceles are easily distinguished from solid lesions. Solid epididymal masses are however non-specific in appearance as neoplastic and inflammatory or granulomatous masses, have variable echogenicity and may appear relatively similar. The inflammatory or granulomatous disease to be considered in the differential diagnosis include: epididymitis, sperm granuloma, sarcoidosis and tuberculosis. As a rule, solid intra-testicular lesions have a high likelihood of malignancy (about 90-95\%) while extra-testicular lesions are usually benign (about 3\%) [4]. Extra-testicular scrotal masses are typically secondary to trauma, infection and inflammation, or benign neoplasms. Ultrasound can easily distinguish intra-testicular from extra-testicular lesions with an accuracy of $95 \%-100 \%$. However, the true identity of epididymal leiomyoma is often masked until histologic study is made [5].

\section{Conclusion}

Testis leiomyoma is a very rare neoplasm. It is very difficult to perform an exact preoperative diagnosis; only histological examination can prove the presence of a leiomyoma. 


\section{References}

1. Cakiroglu B, Ozcan F, Ates L, Aksoy SH. Leiomyoma of the epididymis treated with partial epididymectomy. Urol Ann. 201 4;6:356358.

2. Albert PS, Mininberg DT. Leiomyoma of tunica albugenia of testis. Urology. 1998; 31:344345.

3. Hertzberg BS, Kliewer MA, Hertzberg MA,
Distell BM. Epididymal leiomyoma: Sonographic features. J Ultrasound Med. 1996; 15:797-799.

4. Beccia DJ, Krane RJ, Olsson CA. Clinical management of non-testicular intrascrotal tumors. J Urol. 1976; 1 16:476-479.

5. Spark RP. Leiomyoma of epididymis. Arch Pathol. 1972;93:18-21. 